Transportation Research Forum

Forecasting Cycles in the Transportation Sector

Author(s): Vincent Wenxiong Yao and Brian W. Sloboda

Source: Journal of the Transportation Research Forum, Vol. 44, No. 2 (Summer 2005), pp. 45-60

Published by: Transportation Research Forum

Stable URL: http://www.trforum.org/journal

The Transportation Research Forum, founded in 1958, is an independent, nonprofit organization of transportation professionals who conduct, use, and benefit from research. Its purpose is to provide an impartial meeting ground for carriers, shippers, government officials, consultants, university researchers, suppliers, and others seeking exchange of information and ideas related to both passenger and freight transportation. More information on the Transportation Research Forum can be found on the Web at www.trforum.org. 


\section{FORECASTING CYCLES IN THE TRANSPORTATION SECTOR}

This paper predicted fluctuations in the transportation sector using leading indicators. From 25 initial candidates, we selected seven leading indicators, using various screening techniques and modern time series models. A composite leading index was constructed and found to perform well in predicting transportation reference cycles. The leading index signals downturns in the transportation sector 10 months ahead and upturns six months ahead on average. The index predicted the latest recession in transportation with a lead of 20 months. The analysis also confirms the predictive contents of the composite leading index (CLI) in relation to transportation growth cycles. These evaluation criteria ensure accurate forecasts of the general state of the transportation sector in a timely fashion.

\section{by Vincent Wenxiong Yao and Brian W. Sloboda}

\section{INTRODUCTION}

Business cycle studies play an important role in the decision-making process for government agencies as well as in the private sector. For instance, section 254 of the Gramm-RudmanHollings (GRH, see Table 1 for acronyms) law, passed by the U.S. Congress in December, 1985, provides for "Special Procedures in the Event of a Recession." The document states that the Congressional Budget Office (CBO) Director shall notify the Congress at any time if the $\mathrm{CBO}$ has determined that real economic growth is projected or estimated to be less than zero with respect to each of any two consecutive quarters within a period of six successive quarters starting with the one preceding such notification. This rule, designed as a key condition for the suspension of several GRH provisions, reflects some filtering algorithms ${ }^{1}$ that have long been employed by the National Bureau of Economic Research (NBER) to monitor the business cycles of the U.S. economy. Business cycle study is also utilized as an important input for macroeconomic policies or business planning (Lahiri and Moore, 1991; Zarnowitz, 1992). For instance, businesses implement different strategies during expansions and recessions of the general market.

Burns and Mitchell (1946), the pioneers of NBER studies, define a business cycle as expansions occurring at about the same time in many economic activities, followed by similarly general recessions, contractions, and revivals.
These concurrent movements can be captured by a single, underlying, unobservable variable or index estimated from cyclical indicators. These indicators are grouped into leading, coincident, and lagging categories, according to their tendency to change direction before, during, or after a corresponding change in the general state of the macroeconomy. The composite indices constructed from leading and coincident indicators are called composite leading index (CLI) and composite coincident index (CCI) respectively. CLI is primarily used to forecast the directional change in CCI. Economic theory states that profits are the prime mover in a private enterprise economy and that the recurrence of business cycles of expansion and recession are caused by changes in expectation of profits (de Leeuw, 1991). The CCI and its components measure movements in production and sales; hence, they are concurrent with the current state of the economy. The CLI and its components represent business commitments and expectations regarding labor markets, product markets, and financial markets; thus, they point to the profit outlook.

The NBER currently uses four monthly coincident indicators, together with quarterly Gross Domestic Product (GDP), to define recessions and expansions in the U.S. economy. The Conference Board currently maintains 10 leading indicators to forecast the directional change in the CCI and the general state of the economy. In practice, determining turning points 
Table 1: List of Acronyms

\begin{tabular}{ll}
\hline Short Name & Full Name \\
CLI & Composite Leading Index \\
GRH & Gramm-Rudman-Hollings \\
CBO & Congressional Budget Office \\
NBER & National Bureau of Economic Research \\
CCI & Composite Coincident Index \\
GDP & Gross Domestic Product \\
LYY & Lahiri, Yao, and Young \\
TSI & Transportation Services Index \\
ISM & Institute for Supply Management \\
NAPM & National Association of Purchasing Management \\
OLS & Ordinary Least Squares \\
$\mathrm{H}_{0}$ & Null Hypothesis \\
$\mathrm{H}_{1}$ & Alternative Hypothesis \\
PAT & Phase Average Trend \\
HP & Hodrick and Prescott \\
\hline
\end{tabular}

(peaks or troughs) based on coincident indicators usually involves the resolution of difficulties such as substantial lag or data revision. ${ }^{2}$ For instance, the NBER confirmed the latest recession which began in March 2001 on Nov. 26, 2001, and the latest recovery which began in November, 2001, on July 17, 2003. Leading indicators generally have the advantage of early signaling, timely availability, and freedom from revision. The leading economic indicator approach has also survived repeated testing over time and has been found to be a very effective forecasting technique for predicting economic recessions in other countries (Moore, 1961; Lahiri and Moore, 1991; Zarnowitz, 1992). These studies support the concept that developing leading indicators is an integral component of business cycle studies.

Lahiri, Yao and Young (hereafter, LYY, 2004) studied both business and growth cycles in the U.S. transportation services sector using the economic indicators analysis and modern time series models. Four coincident indicators were selected to represent different aspects of the transportation sector, including a newly developed transportation services index (TSI), ${ }^{3}$ payrolls, personal consumption expenditure, and employment. Based on the CCI, chronologies of both classical business cycles and of growth slowdowns were determined. Previous analyses found that, relative to the economy, business cycles in the transportation sector have an average lead of six months at peaks and an average lag of nearly two months at troughs. That study helps to understand the underlying role of transportation in the initiation and propagation process of economic fluctuations. Although the cycles based on coincident indicators can serve as an important reference for planning and other decision-making processes, they are also subject to substantial lag and revision errors with no exception.

This paper intends to predict the future state of the transportation sector in the United States, using a leading indicator approach. Unlike traditional travel-demand forecasting models in transportation economics, our predicted future value comprises the summarized information of traffic, income, employment, and revenues. It reflects the underlying state of the transportation sector, which can avoid the wrong judgment based on any single measure such as traffic. In particular, leading indicators are very effective in predicting the tendency of directional change in transportation as indicated by LYY (2004). All of the data used in this leading indicator are monthly series, which generate detailed 
and accurate short- and long-term forecasts in a timely fashion. Current transportation forecasts using travel demand models, however, are more long-term. In making these forecasts, we initially examined all the relevant transportation-related indicators as well as the economy-wide leading indicators currently in use, resulting in an initial list of 25 indicators. The selection of valid leading indicators required the employment of different criteria ${ }^{4}$ and statistical procedures.

The balance of this paper is as follows. Section II screens these candidates according to their economic relevance to the reference cycles. Section III refines the list further by testing their ability to Granger-cause the transportation CCI. Section IV checks for the existence of co-movements among a final list of leading indicators, which is one of the two key features of Burns and Mitchell's (1946) business cycle studies. Section $\mathrm{V}$ constructs a composite index of leading indicators to predict the business cycles in the U.S. transportation sector. Section VI examines the prediction of transportation growth cycles, and the last section concludes the paper.

\section{SCREENING BY ECONOMIC RELEVANCE}

Ten leading indicators currently used by the Conference Board cover diverse aspects of the economy: the degree of tightness in the labor market due to employer hiring and firing, new orders in manufacturing for future production, financial information related to short- and longterm interest rate differentials that indicate the effect of monetary policies, stock market performance that indicates investors pessimism or optimism for the future, and consumer expectation for the household's future spending. These components from the leading indicators will be used in the initial assessment.

As a measure of the degree of tightness in the labor market in the transportation sector, the average weekly working hours of production workers in transportation, communications, and public utilities is a good candidate and is included in the initial list. Because transportation equipment provides equipment to the transportation sector, the former has leading information on the latter. In addition to its new orders (NO), some of the coincident or leading indicators for transportation equipment could also have leading indicator value for the transportation services CCI. Those series include shipments ${ }^{5}$, the industrial production index (IP), employment, change in unfilled orders (UO), real aggregate payrolls (Payrolls), and average weekly working hours of production workers (Hours) of the transportation equipment industry.

Since transportation relies heavily on the use of crude oil and petroleum products, the change in the spot price of oil could be an important indicator for supply decisions in transportation both in the short and long runs. In the short run, both pricing and supply capacity of transportation firms will be immediately affected by fuel prices. In the long run, turbulence in the oil market will affect both consumers and investors expectations. In calculating the change in the spot oil price, we have replaced the controversial conventional smoothing procedures with the smoothing filter developed by Statistics Canada. This filter is a weighted autoregression (six lags), with weights estimated from simulation to minimize the lag time and maximize the closeness with the original series.

With respect to the stock market, the current Dow Jones transportation average (DJTA) includes a total of 20 common stocks associated with transportation. Among them are six airlines, five trucking companies, four railroads, two air-freight service providers, and one each from marine transportation, transportation services and industrial service. Like the rationale for including the S\&P 500 in the economic leading indicators, DJTA reflects investors expectations for the profit outlook of transportation industries and should be included.

From the pool of leading indicators for the overall economy, only four of those currently used are included in our list, while the remaining six leading indicators are excluded because similar measures from transportation-related industries have been selected. The included indicators are the consumer sentiment index (CSI) of the University of Michigan, interest rate spread between 10-year treasury bonds and federal funds (Spread); money supply (M2) deflated to constant dollars, and new housing starts (Housing). The CSI reflects consumer attitudes toward the general economy and 
their perceptions about future buying, which covers prospective spending on transportation services.

Batchelor (2001) assessed the predictive value of both the CSI of consumer perceptions and the purchasing management index (PMI) of business perceptions using time-varying Markov-switching models. His empirical study concluded that a rise in consumer confidence reduces the probability of staying in the bad or low-growth state (state 0 ) and thus is useful in predicting peaks. Although the statistical significance over the sample period does not necessarily provide a reliable judgment rule for forecasting the state of the economy, it strongly suggests the usefulness of the CSI as a leading indicator. It would also be a good predictor for household transportation.

The interest rate spread was the dominant constituent series in Stock and Watson's (1991) leading index. Interest spread is pro-cyclical because it measures, among other things, the default risk on private securities. Also both interest spread and deflated M2 are indicators of the effects of monetary policies and would also be connected with demand for household and business transportation because new housing starts represents the beginning of residential construction. That is, construction directly results in the hiring of workers and purchase of household appliances and equipment. Thus, new housing starts can create direct demand for transportation and industrial services, which would affect the economy.

The purchasing management index (PMI) prepared by the Institute for Supply Management (ISM, formerly National Association of Purchasing Management or NAPM) represents attitudes of business toward future profits. Its five components: promptness of deliveries, inventories, new orders, production, and employment diffusion indexes represent five different aspects of the direction of economic activity in manufacturing industries. They all have similar cyclical movements.

Batchelor (2001) found that a fall in PMIall index leads to a fall in the probability of the good state (expansion). Klein and Moore (1991) found that PMI-new orders index lags the actual volume of new orders by a few months, but its movements are much smoother; PMI-inventory index closely matches the swings in inventory change and hence is a leading indicator of business cycles; the PMI-all index matches every business cycle with an average lead time of three months between 1948 and 1988. In addition, diffusion indexes have great advantages such as prompt availability, revision-free, and simplicity. ${ }^{6}$ The PMI-delivery index is currently included as one of the leading indicators. Among these PMI indexes, PMI-inventory is preferred for the preceding reasons.

Theoretically, the transportation sector plays the major role in moving both final goods and supplies and materials to build up inventories and inventory cycles are the dominant feature of business cycles in the overall economy. Therefore, there should be a reasonable leadand-lag relationship between the change in inventory in the economy and activities in the transportation sector. But because there are different commodities in the inventories, it is not clear which indicator of inventory will do a better job. Tamm (1991) evaluated the inventory series of the Department of Commerce and the NAPM (now ISM) inventory diffusion index for a better measure of cyclical movements of inventory. Regardless of its timeliness, Tamm argues that the PMI index can be useful for its supplemental role to the NBER inventory data series. Blinder and Maccini (1991) show that retail inventory and manufacturers purchased material and supplies are by far the most volatile components of inventory investment, which is exactly the coverage of the PMI-inventory index. In addition, the PMI-inventory seems to have fewer false signals than other PMI indexes. The PMI, then, would serve as a good leading indicator for the economy.

Following the above rationales, there are a total of 15 potential leading indicators for the transportation sector. They are reported in Table 2 together with their data sources.

\section{TESTS FOR PREDICTIVE CONTENT OF INDIVIDUAL INDICATORS}

In a qualified leading indicator, its predictive content for the composite coincident index should be emphasized over other factors. Therefore, these variables are screened by testing their ability to Granger-cause (Granger, 1969) 
Table 2: Potential Leading Indicators for the Transportation Sector

\begin{tabular}{|c|c|c|}
\hline Short Names & Full Names & Sources \\
\hline$\overline{\mathrm{CSI}}$ & Consumer Sentiment Index & University of Michigan \\
\hline PMI-Inventory & $\begin{array}{l}\text { Purchasing Management Index - Inventory } \\
\text { Component }\end{array}$ & Institute for Supply Management \\
\hline Housing & New Housing Starts & Bureau of Census \\
\hline NO (TE) & New Orders for Transportation Equipment & Bureau of Census \\
\hline Payrolls (TE) & $\begin{array}{l}\text { Real Aggregate Payrolls of Transportation } \\
\text { Equipment }\end{array}$ & Bureau of Labor Statistics \\
\hline Spread & $\begin{array}{l}\text { Interest Rate Spread between } 10 \text {-year Treasury } \\
\text { Bonds and Federal Funds }\end{array}$ & Federal Reserve \\
\hline Hours (TE) & $\begin{array}{l}\text { Average Working Hours of Production Workers } \\
\text { in Transportation Equipment }\end{array}$ & Bureau of Labor Statistics \\
\hline IP (TE) & $\begin{array}{l}\text { Industrial Production Index of Transportation } \\
\text { Equipment }\end{array}$ & Federal Reserve \\
\hline Shipments (TE) & Real Shipments of Transportation Equipment & Bureau of Census \\
\hline DJTA & $\begin{array}{l}\text { Dow Jones Transportation Average ( } 20 \text { Common } \\
\text { Stocks) }\end{array}$ & Dow Jones \\
\hline Hours (TP) & $\begin{array}{l}\text { Average Working Hours of Production Workers } \\
\text { in Transportation and Public Utilities }\end{array}$ & Bureau of Labor Statistics \\
\hline UO (TE) & $\begin{array}{l}\text { Change in Unfilled Orders for Transportation } \\
\text { Equipment }\end{array}$ & Bureau of Census \\
\hline Employment (TE) & Employment in Transportation Equipment & Bureau of Labor Statistics \\
\hline M2 & Real Money Supply (M2) & Federal Reserve \\
\hline Oil & Change in Spot Oil Price & Dow Jones Energy Service \\
\hline
\end{tabular}

the transportation CCI. ${ }^{7}$ Applying this procedure eliminated five time series from the list. Series that Granger-cause the transportation $\mathrm{CCI}$ at the $5 \%$ level of significance are CSI, interest rate spread, new housing starts, Hours (TE), NO (TE), IP (TE), Shipments (TE), Payrolls (TE), DJTA, and PMI-inventory. The very small probabilities of PMI-inventory and CSI of not rejecting null hypothesis $\left(\mathrm{H}_{0}\right)$ in the Granger causality tests also validate the compelling predictive content of these two diffusion indexes. This bivariate analysis is similar to Stock and Watson (1991) in selecting leading indicators for the economy.

In the next step, multivariate analysis was used to obtain the effects of additional variables compared with a base model. The purpose of doing this was to identify which variables add "new" information in addition to those well-established variables like CSI and PMIinventory. The study considered three base models, starting with the regression of growth of the transportation CCI on four of its own lags and those of the CSI (base model 1), then CSI and PMI-inventory (base model 2), CSI, PMIinventory index, and new housing starts (base model 3). The reason for using these three variables in the base models was that they are aggregate economy variables and had the most significant predictive content in the first step. Thus, suppose $\mathrm{X}$ is the variable to be tested, three base models are defined as the following:

(1) Base model 1:

$$
\begin{aligned}
\Delta C C I_{t}= & \alpha_{1} \Delta C C I_{t 1}+\alpha_{2} \Delta C C I_{t 2}+\alpha_{3} \Delta C C I_{t 3}+\alpha_{4} \Delta C C I_{t 4}+ \\
& \beta_{1} C S I_{t 1}+\beta_{2} C S I_{t 2}+\beta_{3} C S I_{t 3}+\beta_{4} C S I_{t 4}+ \\
& \gamma_{1} X_{t 1}+\gamma_{2} X_{t 2}+\gamma_{3} X_{t 3}+\gamma_{4} X_{t 4}
\end{aligned}
$$

(2) Base model 2: $\quad \Delta C C I_{t}=\alpha_{1} \Delta C C I_{t 1}+\alpha_{2} \Delta C C I_{t_{2}}+\alpha_{3} \Delta C C I_{t_{3}}+\alpha_{4} \Delta C C I_{t_{4}}+$

$$
\begin{aligned}
& \beta_{1} C S I_{t 1}+\beta_{2} C S I_{t 2}+\beta_{3} C S I_{t 3}+\beta_{4} C S I_{t 4}+ \\
& \beta_{5} P M I_{t 1}+\beta_{6} P_{12}+\beta_{7} P_{t} M I_{t 3}+\beta_{8} P M I_{t 4}+ \\
& \gamma_{1} X_{t 1}+\gamma_{2} X_{t 2}+\gamma_{3} X_{t 3}+\gamma_{4} X_{t 4}
\end{aligned}
$$


(3) Base model 3:

$$
\begin{aligned}
& \Delta C C I_{t} \quad \alpha_{1} \Delta C C I_{t 1}+\alpha_{2} \Delta C C I_{t 2}+\alpha_{3} \Delta C C I_{t_{3}}+\alpha_{4} \Delta C C I_{t 4}+
\end{aligned}
$$

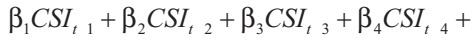

$$
\begin{aligned}
& \beta_{5} P M I_{t 1}+\beta_{6} P M I_{t 2}+\beta_{7} P M I_{t 3}+\beta_{8} P M I_{t 4}+ \\
& \beta_{9} \text {HOUSING }_{t 1}+\beta_{10} \text {HOUSING }_{t 2}+\beta_{11} \text { HOUSING }_{t 3}+\beta_{12} \text { HOUSING }_{t 4}+ \\
& \gamma_{1} X_{t 1}+\gamma_{2} X_{t 2}+\gamma_{3} X_{t 3}+\gamma_{4} X_{t 4}
\end{aligned}
$$

In the definition of the Granger causality test, $X$ is considered to have additional predictive power to CCI if $H_{0}$ that $\gamma_{1}=\gamma_{2}=\gamma_{3}=\gamma_{4}=0$ is rejected in an $F$ test. The study also considered whether the adjusted $\mathrm{R}^{2}$ was increased by including six and 12 lags, respectively, of a new variable. Table 3 shows the resulting $p$-value and adjusted $\mathrm{R}^{2}$ where * marks the additional series that has only increased adjusted $\mathrm{R}^{2}$, and ** marks the variables that increase the adjusted $\mathrm{R}^{2}$ and pass the $F$ test. In base model 1, PMI-inventory index, interest rate spread, and new housing starts has additional predictive power in the Granger causality test and are marked with **. Only one transportation variable, TE's payrolls, increased the adjusted $\mathrm{R}^{2}$, and is marked with *. In base model 2 , new housing starts is the only variable that Granger-causes growth of the transportation $\mathrm{CCI}$ in addition to the two diffusion indexes. Interest rate spread, TE's new orders, payrolls, and shipments, and DJTA have all increased the adjusted $\mathrm{R}^{2}$. In base model 3, only TE's shipments Granger-cause the dependent variable with six lags at the $5 \%$ level of significance in addition to the two diffusion indexes and new housing starts. Interest rate spread, TE's new orders, and production, and DJTA increased the adjusted $\mathrm{R}^{2}$ but failed to reject $H_{0}$ of the Granger causality test. Provided that the CSI and/or PMIinventory index (base model 2) reflect the most valuable information in the list, TE's weekly working hours generated little new information and thus should be removed. TE's production is marginal and was held for the next selection procedure.

\section{TESTS FOR THE SYNCHRONIZATION OF CYCLES}

Co-movement or common cycle is one of the two key features in the Burns and Mitchell (1946) definition of business cycles. The other is the transition between different states. Extraction of the co-movements out of coincident and leading indicators into a single series leads to the CCI and CLI respectively. Harding and Pagan (2002) developed the index of concordance which can test for the existence of a common cycle between the leading indicators $x$ and $y$ :

$$
\text { (4) } I=\frac{1}{T}\left\{\sum_{t}^{T} S_{x t} S_{y t}+\sum_{t}^{T}\left(1-S_{x t}\right)\left(1-S_{y t}\right)\right\} \text {. }
$$

where $\mathrm{S}_{x t}$ and $\mathrm{S}_{y t}$ are binary variables that take the value 1 for contractions (the peak to trough distance) and 0 for expansion periods, based on the turning points defined for series $x$ and $y$ respectively using the NBER procedure (Bry and Boschan, 1971). T is the sample size. Thus, $I$ measures the fraction that two coincident indicators are simultaneously in the same state, which is distinct from correlation coefficient. ${ }^{8}$

The index of concordance is calculated between each pair of candidates for leading indicators. Among 28 indexes of concordance, there are 12 that are less than 0.70 ; alternatively, nine pairs of variables have correlations below 0.25 . All weak correlations are related to interest rate spread and new housing starts. The former series even has negative correlation with most of the others. The rest of the concordances or correlations are strong because the correlations are above .60 .

To test the statistical significance of the synchronization of these cycles, a statistical test by Harding and Pagan (2002) was applied. Therefore, the null hypothesis to be tested is $\mathrm{H}_{0}: \rho_{s}=0$, i.e., no synchronization against the alternative hypothesis $\left(\mathrm{H}_{1}\right)$ that there is significant synchronization between specific cycles of each indicator. $\hat{\rho}_{s}$ is obtained from the regression as given in Harding and Pagan (2002):

$$
\text { (5) } \frac{S_{y t}}{\sigma_{S_{y}}}=a_{1}+\rho_{S} \frac{S_{x t}}{\sigma_{S_{x}}}+u_{t} \text {. }
$$

Standard $t$-statistics are based on ordinary least squares (OLS) under the assumption of no serial correlation and heteroskedasticity, while robust $t$ is based on Newey-West heteroskedasticity, autocorrelation consistent standard errors and covariance to account for 


\section{Table 3: Effects of Including Additional Variables in the CLI Base Models}

\begin{tabular}{|c|c|c|c|c|}
\hline & \multicolumn{2}{|c|}{ P-value } & \multicolumn{2}{|c|}{$\overline{\mathrm{R}}^{2}$} \\
\hline & $6 \mathrm{lag}$ & $12 \mathrm{lag}$ & 6 lag & $12 \mathrm{lag}$ \\
\hline Base model 1: CSI & & & 0.144 & 0.152 \\
\hline PMI-Inventory** & 0.003 & 0.011 & 0.189 & 0.19 \\
\hline Housing** & 0.017 & 0.102 & 0.175 & 0.166 \\
\hline NO (TE) & 0.390 & 0.637 & 0.145 & 0.137 \\
\hline Payrolls (TE)* & 0.322 & 0.084 & 0.147 & 0.174 \\
\hline Spread** & 0.037 & 0.098 & 0.168 & 0.166 \\
\hline Hours (TE) & 0.811 & 0.831 & 0.134 & 0.129 \\
\hline IP (TE) & 0.272 & 0.716 & 0.149 & 0.134 \\
\hline Shipments (TE) & 0.115 & 0.412 & 0.158 & 0.146 \\
\hline \multirow[t]{3}{*}{ DJTA } & 0.450 & 0.376 & 0.143 & 0.147 \\
\hline & \multicolumn{2}{|c|}{ P-value } & \multicolumn{2}{|c|}{$\overline{\mathrm{R}}^{2}$} \\
\hline & 6 lag & 12 lag & 6 lag & $12 \mathrm{lag}$ \\
\hline \multicolumn{3}{|c|}{ Base model 2: CSI + PMI-Inventory } & 0.189 & 0.183 \\
\hline Housing** & 0.000 & 0.005 & 0.250 & 0.241 \\
\hline NO $(\mathrm{TE})^{*}$ & 0.118 & 0.452 & 0.189 & 0.209 \\
\hline Payrolls (TE)* & 0.157 & 0.153 & 0.200 & 0.203 \\
\hline Spread* & 0.065 & 0.218 & 0.208 & 0.201 \\
\hline Hours (TE) & 0.720 & 0.720 & 0.182 & 0.179 \\
\hline IP (TE) & 0.340 & 0.838 & 0.192 & 0.174 \\
\hline Shipments (TE)* & 0.139 & 0.574 & 0.201 & 0.185 \\
\hline \multirow[t]{3}{*}{ DJTA* } & 0.459 & 0.367 & 0.189 & 0.193 \\
\hline & \multicolumn{2}{|c|}{ P-value } & \multicolumn{2}{|c|}{$\overline{\mathrm{R}}^{2}$} \\
\hline & 6 lag & 12 lag & 6 lag & 12 lag \\
\hline \multicolumn{3}{|c|}{ Base model 3 : CSI + PMI-Inventory + Housing } & 0.251 & 0.233 \\
\hline $\mathrm{NO}(\mathrm{TE})^{*}$ & 0.392 & 0.109 & 0.252 & 0.270 \\
\hline Payrolls (TE) & 0.487 & 0.344 & 0.249 & 0.248 \\
\hline Spread* & 0.417 & 0.575 & 0.251 & 0.246 \\
\hline Hour (TE) & 0.924 & 0.813 & 0.238 & 0.237 \\
\hline $\mathrm{IP}(\mathrm{TE})^{*}$ & 0.417 & 0.866 & 0.251 & 0.235 \\
\hline Shipments $(\mathrm{TE})^{*}$ & 0.047 & 0.348 & 0.271 & 0.255 \\
\hline DJTA* & 0.401 & 0.358 & 0.251 & 0.254 \\
\hline
\end{tabular}

Note:

1) Columns 1 and 2 present p-values for the F-test of the null hypothesis that the coefficients on the CLI candidate variables are zeros in an OLS regression of the one-month growth rate in the transportation CCI on the base set of two diffusion indexes, four lags of the dependent variable, and 6 and 12 lags, respectively, of the candidate variable.

2) * indicates the CLI candidate variable that increases the $\overline{\mathrm{R}}^{2}$ in explaining the dependent variable in addition to the base model; ** indicates the CLI candidate variable that both increases the $\overline{\mathrm{R}}^{2}$ and reject the $H_{0}$ that the coefficients of its lags are all zeros. 
possible heteroskedasticity and autocorrelation in the error term in equation 5. Considering the high serial correlation among the variables, robust $t$ could be preferable. At the 5\% significance level, $t$-statistics of interest rate spread with other variables cannot reject $H_{0}$ against $H_{1}$. At the $1 \%$ level of significance, $t$-statistics for new housing starts with other variables cannot reject $H_{0}$ except for its relationship with TE's production. The correlation between CSI and DJTA is very close to the $1 \%$ critical value, but all of their other correlations are statistically significant. Therefore, interest rate spread and new housing starts are removed from the list for lack of common cycles with the seven other series. The remaining seven variables are our finalists for leading indicators to predict the coincident index of the U.S. transportation sector. They are plotted in Figure 1 where shaded areas represent the recessions of the transportation sector as defined by LYY (2004).

\section{The Predictive Power of the Constructed Transportation CLI}

Based on these seven leading indicators, a leading index was constructed using the conventional NBER approach (Conference Board, 2001). Standardization factors of leading indicators used for constructing an NBER index are the inverse of the standard deviation of each series, as reported in Table 4. The constructed leading index for the transportation sector is a weighted average of the leading indicators transformed symmetric month-to-month change, then converted back to a level index (the transportation CLI). It is plotted in Figure 2 against the transportation CCI. The CLI appears to lead both the peaks and troughs of all recessions in the CCI.

The exact lead-and-lag relation of the transportation CLI relative to transportation business cycle chronologies is reported in Table 5. During the latest transportation recession beginning in November, 2000, and ending in December, 2001, the leading index led the transportation coincident index by 20 months at the peak and three months at the trough. Overall, the leading index of the U.S. transportation sector leads its CCI, on average, by 10 months at the peaks and six months at the troughs. The CLI also signaled recessions in February, 1995, to
February, 1996, and May, 1998, to July, 1998, when there were no recessions in the U.S. transportation sector. However, these extra turning points are very short and mild. The extra recession signal in 1995 is associated with a growth cycle recession instead of a full-fledged recession in the transportation sector (Lahiri et al., 2003). The other false signal might be caused by a sector-wide temporary shock, as seen in most transportation indicators.

Figure 4 compares the Conference Board CLI for the overall economy and transportation CLI. The two leading indexes are similar during two recessions in the early 1980s, but they are different in the rest of the sample period. Firstly, the transportation CLI predicted the 1990 recession with a much clearer signal in February 1989 while the peak in the Conference Board CLI was very difficult to distinguish. Secondly, the transportation CLI marked a downturn in 1998 which was unique to transportation. Thirdly, corresponding to a much earlier recession in transportation in 2000 than in the overall economy, the transportation CLI had an earlier signal (March 1999) than the Conference Board CLI. Last, the transportation CCI has reflected a much weaker recovery in transportation than the overall economy since 2001 as well as an additional downturn beginning 2002. These events were predicted by the transportation CLI, not the Conference Board CLI. Therefore, the transportation CLI is more powerful in predicting cycles in the transportation sector.

The lead-time analysis presented above does not take into account either the lag involved in obtaining the data necessary to construct the Conference Board CLI or the necessity of employing a non-parametric filter rule such as the two-consecutive-quarter-declines rule for signaling a downturn. With almost no exception, forecasting techniques often involve a tradeoff of accuracy for timeliness and false signals (Lahiri and Wang, 1994).

\section{PREDICTING GROWTH CYCLES IN THE TRANSPORTATION SECTOR}

In addition to identifying economy-wide recessions, the NBER has a long-standing tradition of also identifying growth cycles (see Zarnowitz and Ozyildirim, 2002). These are the periods 
Table 4: Standardization Factors for Constructing Transportation CLI

\begin{tabular}{ll}
\hline U.S. Transportation & Factors \\
Leading Indicators & (Up to 12/2003) \\
\hline DJTA (20 stocks) & 0.098 \\
PMI-inventory diffusion index (PMF Inventory) & 0.091 \\
NO (TE) & 0.058 \\
Shipments (TE) & 0.140 \\
IP (TE) & 0.256 \\
Payrolls (TE) & 0.220 \\
Consumer Sentiment Index (CSI) & 0.137 \\
\hline
\end{tabular}

Table 5: Predicting Transportation Growth Cycles

\begin{tabular}{|c|c|c|c|c|c|c|c|}
\hline \multicolumn{2}{|c|}{$\begin{array}{l}\text { Transportation } \\
\text { Business Cycles }\end{array}$} & \multicolumn{2}{|c|}{$\begin{array}{c}\text { Leads ( ) and Lags }(+) \text {, in } \\
\text { months, of the } \\
\text { Transportation Leading } \\
\text { Index relative to } \\
\text { Transportation Business } \\
\text { Cycles }\end{array}$} & \multicolumn{2}{|c|}{$\begin{array}{l}\text { Transportation } \\
\text { Growth Cycles }\end{array}$} & \multicolumn{2}{|c|}{$\begin{array}{c}\text { Leads ( ) and Lags (+), in } \\
\text { months, of the } \\
\text { Transportation Leading } \\
\text { Index relative to } \\
\text { Transportation Growth } \\
\text { Cycles }\end{array}$} \\
\hline $\mathrm{P}$ & $\mathrm{T}$ & $\mathrm{P}$ & $\mathrm{T}$ & $\mathrm{P}$ & $\mathrm{T}$ & $\mathrm{P}$ & $\mathrm{T}$ \\
\hline 03/79 & $08 / 80$ & 4 & 1 & $01 / 79$ & $08 / 80$ & 2 & 3 \\
\hline \multirow[t]{2}{*}{$01 / 81$} & $2 / 83$ & 1 & 13 & $01 / 81$ & $02 / 83$ & 2 & 4 \\
\hline & & & & $06 / 84$ & $01 / 87$ & 6 & 20 \\
\hline \multirow[t]{2}{*}{$05 / 90$} & $06 / 91$ & 16 & 6 & $12 / 88$ & $04 / 92$ & 1 & 16 \\
\hline & & & & $12 / 94$ & $08 / 97$ & 11 & 17 \\
\hline $11 / 00$ & $12 / 01$ & 20 & 3 & $02 / 00$ & $11 / 01$ & 12 & 2 \\
\hline \multicolumn{2}{|c|}{ Mean } & 10 & 6 & \multicolumn{2}{|c|}{ Mean } & 4 & 10 \\
\hline \multicolumn{2}{|c|}{ Median } & 10 & 6 & \multicolumn{2}{|c|}{ Median } & 5 & 10 \\
\hline \multicolumn{2}{|c|}{ Std Dev } & 9 & 6 & \multicolumn{2}{|c|}{ Std Dev } & 5 & 8 \\
\hline
\end{tabular}

Note: $\mathrm{P}=$ Peak of cycle; $\mathrm{T}=$ Trough of cycle 


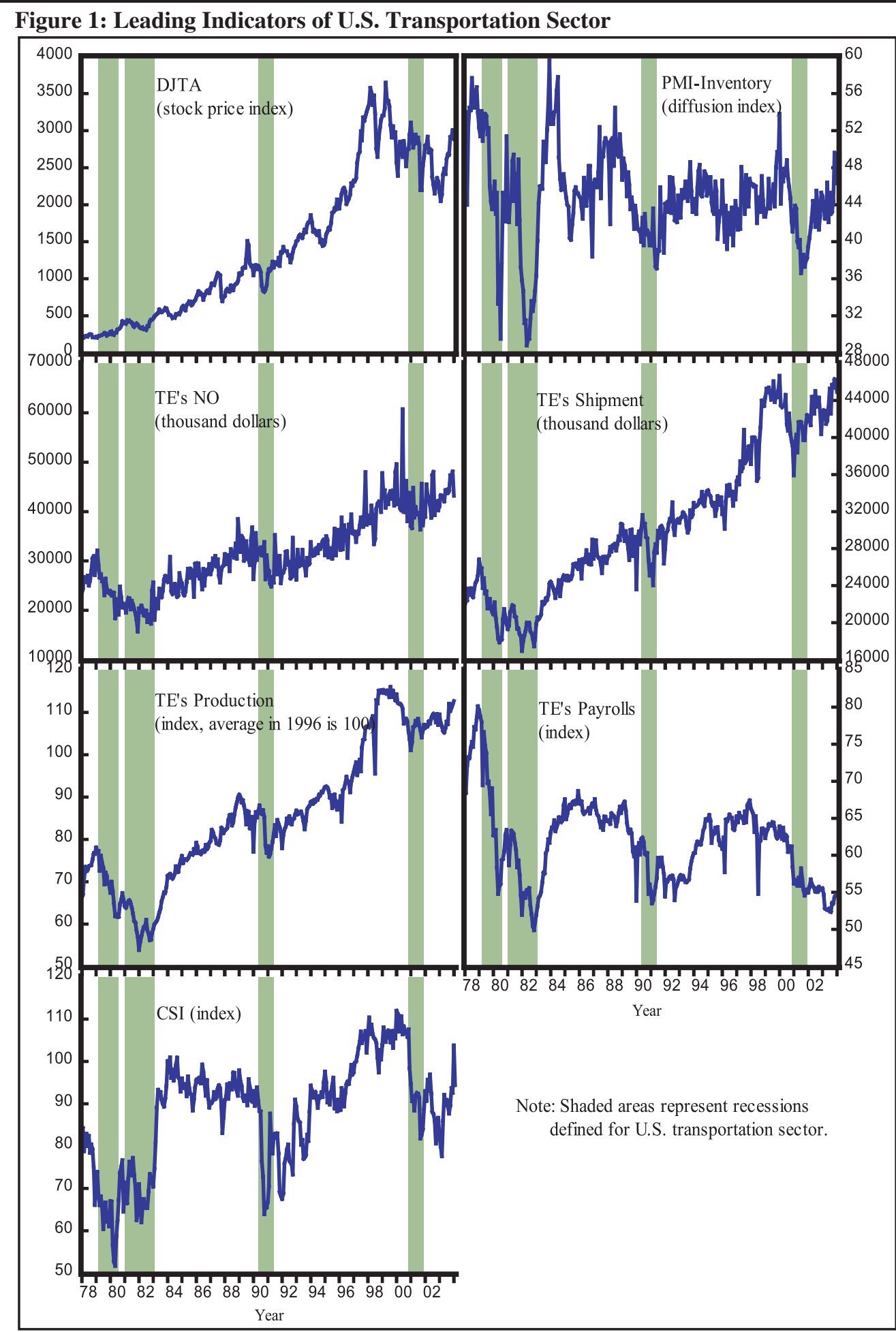


Figure 2: Composite Leading Index for the U.S. Transportation Sector

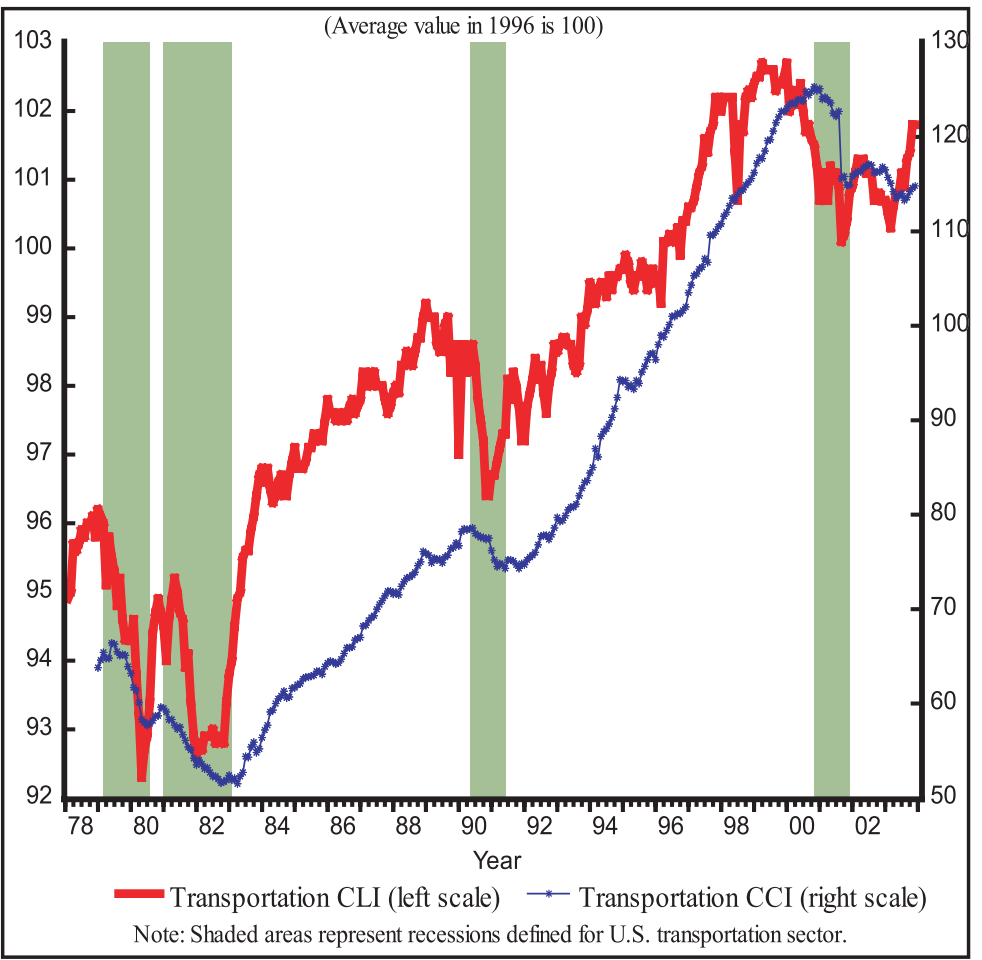

Figure 3: Growth Cycles of Transportation CLI

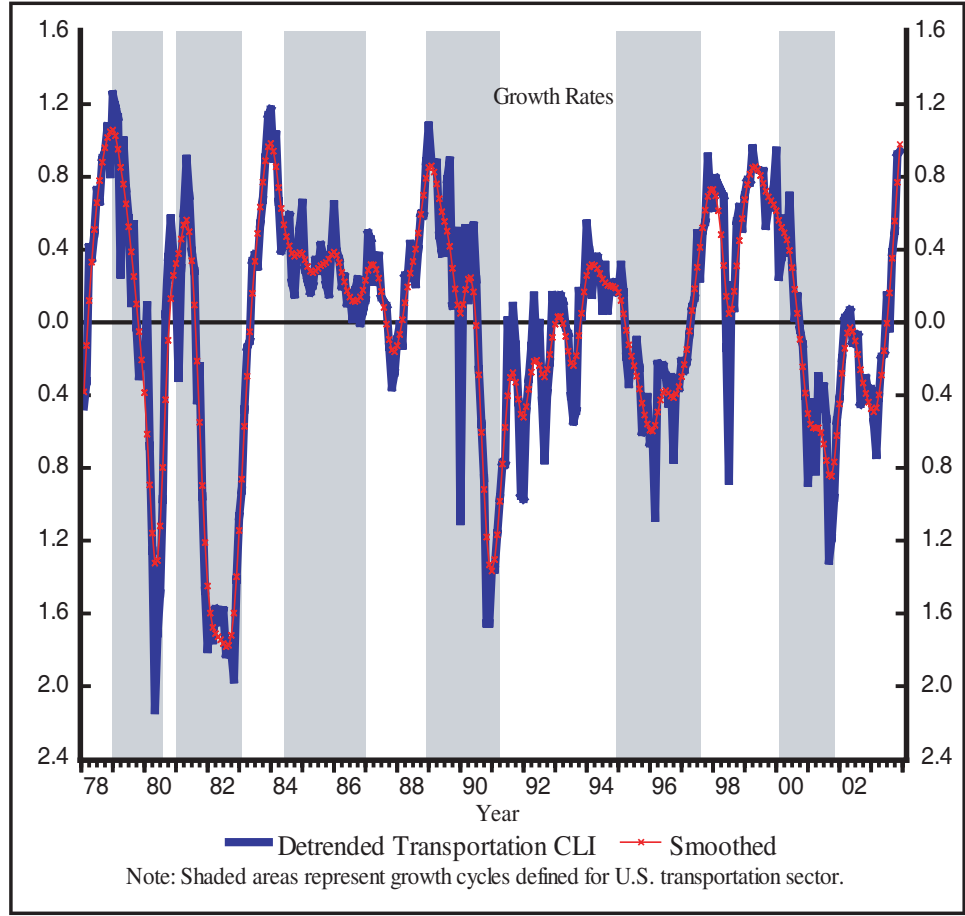


Figure 4: Conference Board CLI and Transportation CLI

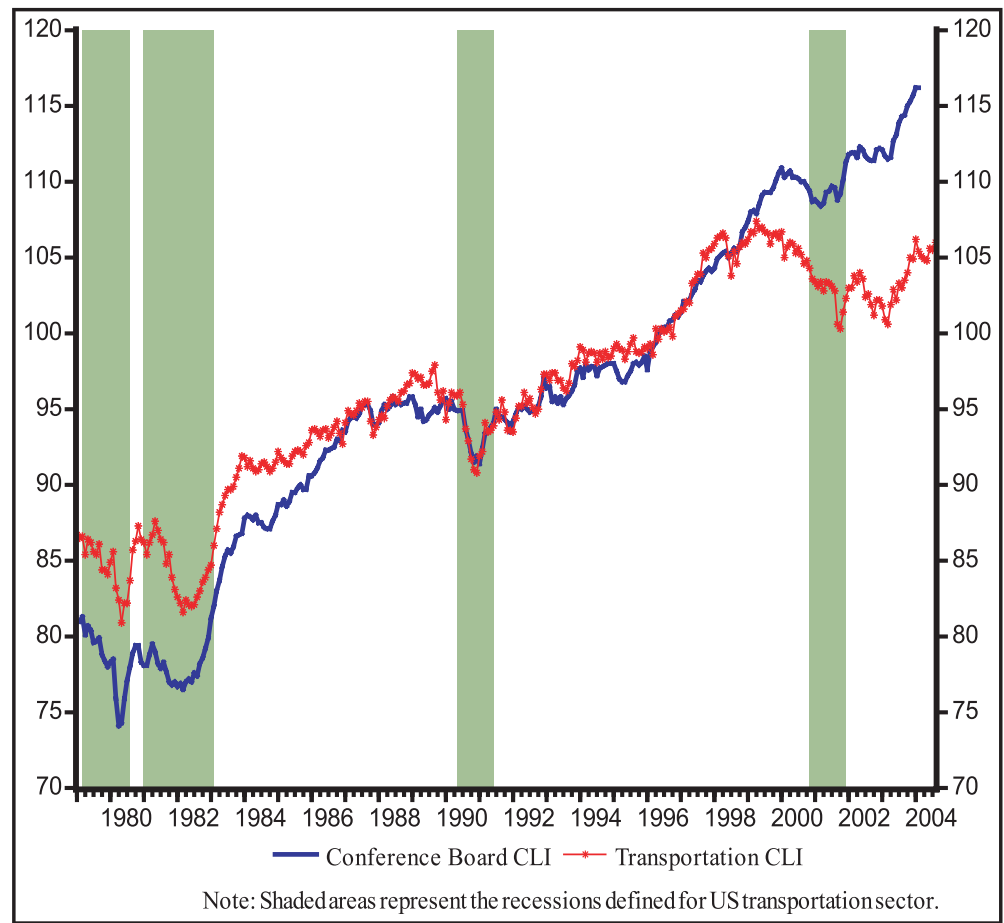

when the economy undergoes alternating periods of deceleration and acceleration of growth that often do not develop into full-fledged recessions, which are periods with negative growth.

The conventional NBER algorithm to define growth cycles is the Phase Average Trend (PAT) method as developed by Boschan and Ebanks (1978). Because the work involved in the estimation of PAT is arduous, the Hodrick and Prescott filter would serve as a good alternative. Hodrick and Prescott (1997) developed a filter in which the trend value $S_{t}$ of the de-seasonalized data $Y_{t}$ can be estimated by minimizing

$$
\text { (6) } \sum_{t=1}^{T}\left(y_{t} \boldsymbol{S}_{t}\right)^{2}+\lambda \sum_{t=2}^{T}\left(( \begin{array} { l l l l } 
{ \boldsymbol { S } _ { t + 1 } } & { \boldsymbol { S } _ { t } }
\end{array} ) \left(\begin{array}{ll}
\boldsymbol{S}_{t} & \left.\left.\boldsymbol{S}_{t}\right)\right)^{2}
\end{array}\right.\right.
$$

where $\mathrm{T}$ is the sample size. The penalty parameter $\lambda$ controls the smoothness of the series, which is a positive number and places a penalty against the variability in the growth component. ${ }^{9}$ Growth cycles are then defined, based on the deviation from the trend of original seasonally adjusted data series, i.e., $Y_{t}-S_{t}$. LYY (2004) study the growth cycles of the transportation sector and find that deviation from PAT and from the Hodrick-Prescott trend appear to be similar. From this assessment, the different phases are clearly identified with the assistance of the zero line in Figure 3. Over our sample period, there are six such growth cycle recessions in the transportation sector. Four of them developed into recessions, while the other two are merely stand-alone slowdowns. Like business cycles, these slowdowns in the transportation sector are also longer than those in the aggregate economy; they peak ahead of the economy by almost three months on the average, while at troughs they lag by two months. Growth cycles of this sector are well-synchronized with those of the economy but with slightly longer durations.

Growth cycles of the transportation sector were defined based on the deviation from PAT of the transportation CCI. Growth cycles from the transportation CLI were then used to predict them based on the deviation from its HodrickPrescott trend, as plotted in Figure 3. The exact lead-and-lag relationship of growth cycles of transportation CLI relative to the transportation sector is also reported in Table 5. Given the growth cycles for the U.S. transportation sector, 
the transportation CCI leads the economy growth cycle, on average, by four months at peaks and 10 months at troughs. The latest growth cycle recession has a lead of 12 months at the peak and two months at the trough.

\section{CONCLUSIONS}

LYY (2004) define transportation reference cycles as representing the general state of the transportation sector. These cycles can be useful to the decision-making process in transportation in both short-run and middle-range forecasting. This paper predicted the reference cycle for the U.S. transportation sector by selecting leading indicators and developing a leading index. The selection of indicators is an important process in the leading economic indicator literature. The paper adopted various techniques and tests for this purpose, including economic theory, graphic investigation, Granger-causality tests in bivariate and multivariate specifications for predictive content, and directional change analysis to test the co-movements among a group of indicators.
A sufficiently long lead-time between turning points in the series and those of reference cycles that occurs consistently is the essential property of valid leading indicators. Therefore, the paper can be considered a renovation of the long tradition of NBER economic indicator studies, but the techniques are applied to the U.S. transportation sector and not the aggregate economy.

Out of 25 indicators included in the initial list, seven survived various screening procedures. Based on these indicators, the transportation CLI was developed using the conventional NBER approach. The leading index of the United States transportation sector leads its CCI, on average, by 10 months at the peaks and six months at the troughs. For the latest recession, the former signaled the start of a recession 20 months earlier and the recovery three months ahead. The predictive content of the CLI for transportation growth cycles was also tested. The CLI can signal a change in CCI earlier, on average, by four months at peaks and 10 months at troughs.

\section{Endnotes}

1. NBER filtering algorithm states that a single phase should be no shorter than six months, and a complete cycle should last at least 12 months before the next cycle (Bry \& Boschan, 1971).

2. Early versions of the GDP estimates are based on partial and incomplete source data. Subsequent GDP estimates incorporate increasingly comprehensive and improved source data, which may reverse the sign of the growth rate of GDP.

3. TSI is a new output measure for the U.S. transportation sector. It is a chained-type aggregate index of both freight and passenger traffic of trucking, railroads, airlines, transit, and pipelines. It is produced at the U.S. Bureau of Transportation Statistics since March 2004.

4. These criteria are discussed in detail in Zarnowitz and Boschan (1975, pp. 171-3) and include: a) economic significance, b) statistical adequacy, c) conformity to historical business cycles, d) consistency of timing during cycles, e) smoothness, and f) currency.

5. Both new orders and shipments are estimates of manufacturers' orders data prepared by the U.S. Bureau of the Census. Data are based on Standard Industrial Classification (SIC) from 2001-2003 while the North American Industry Classification System (NAICS)-based data are reported from 1992-2002. According to the BEA's Handbook of Cyclical Indicators (1984), the constant-dollar orders series of transportation equipment are deflated, using the producer price index for capital equipment. Because TE's new orders contain too much high frequency noise, it was smoothed by the filter $\mathrm{S}(\mathrm{L})=1+2 \mathrm{~L}+2 \mathrm{~L}^{2}+\mathrm{L}^{3}$ as developed by Statistics Canada. 
6. The diffusion index is calculated from survey results on changes rather than levels of economic activity. For example, ISM surveys ask purchasing managers if their inventories "increased," "were the same," or "decreased" in the current period compared to last month, and the inventory diffusion index is based on the sum of the respondents answering "increase" or "decrease."

7. The Granger-causality test checks the null hypothesis that the coefficients of both current and lag values of explanatory variables are not statistically significant in a linear regression of the dependent variable. Thus it is an F-test. Granger-causality is different from the standard definition of causality. It refers to whether one event takes place earlier or provides information about the future movements of the other.

8. If $S_{v t}$ is defined based on the NBER turning points and $S_{x t}$ for any of the other coincident indicators. $I$ would be equal unity if the series are pro-cyclical. Another advantage of this approach is that the detrending of the series is not necessary since it is well-defined for non-stationary processes.

9. The first term in the equation represents the cyclical movement (difference between a time series and its trend), and the second term represents the second order change or smoothness of the trend. Thus, the minimization of the equation amounts to balancing between the closeness of $y_{t}$ to its tobe-estimated trend, and the smoothness of this trend. $\lambda$ is the weighting parameter emphasizing smoothness of trend relative to closeness, so it is a unit-free number relative to 1 (weight emphasizing the closeness).

\section{References}

Batchelor, R. "Confidence Indexes and the Probability of Recession: A Markov Switching Model." Indian Economic Review XXXVI(1), (2001): 107-124.

Blinder, A.S. and L.J. Maccini. "Taking Stock: A Critical Assessment of Recent Research on Inventories." Journal of Economic Perspectives 5(1), (1991): 73-96.

Boschan, C. and W.W. Ebanks. "The Phase-Average Trend: A New Way of Measuring Economic Growth." Proceedings of the Business and Economic Statistics Section. Washington, D.C.: American Statistical Association, 1978.

Bry, G. and C. Boschan. Cyclical Analysis of Time Series: Selected Procedures and Computer Programs. NBER Technical Paper 20, 1971.

Bureau of Economics Analysis, U.S. Department of Commerce. Handbook of Cyclical Indicators, 1984.

Burns, A.F. and W.C. Mitchell. Measuring Business Cycles. National Bureau of Economic Research, New York, 1946.

Conference Board. "Calculating the Composite Indexes." Available at www.conference-board.org, revised in January 2001.

de Leeuw, F. "Toward a Theory of Leading Indicators.” Kajal Lahiri and Geoffrey H. Moore eds. Leading Economic Indicators: New Approaches and Forecasting Records. Cambridge: Cambridge University Press (1991): 15-56. 
Granger, C.W.J. "Investigating Causal Relations by Econometric Methods and Cross-Spectral Methods." Econometrica 34, (1969): 424-438.

Harding, D. and A. Pagan. "Dissecting the Cycle: A Methodological Investigation." Journal of Monetary Economics 49, (2002): 365-381.

Hodrick, R.J. and E.C. Prescott. "Postwar U.S. Business Cycles: An Empirical Investigation." Journal of Money, Credit, and Banking 29, (1997): 1-17.

Klein, P.A. and G.H. Moore. "Purchasing Management Survey Data: Their Value as Leading Indicators." Kajal Lahiri and Geoffrey H. Moore eds. Leading Economic Indicators: New Approaches and Forecasting Records. Cambridge: Cambridge University Press (1991): 403-428.

Lahiri, K. and G.H. Moore. Leading Economic Indicators: New Approaches and Forecasting Records. (eds.), Cambridge: Cambridge University Press, 1991.

Lahiri, K., H.O. Stekler, W. Yao, and P. Young. "Monthly Output Index for the US Transportation Sector." Journal of Transportation and Statistics 6(2/3), (2003): 1-27.

Lahiri, K. and J. Wang. "Predicting Cyclical Turning Points with Leading Index in a Markov Switching Model. Journal of Forecasting 13, (1994): 245-263.

Lahiri, K., W. Yao, and P. Young. "Transportation and the Economy: Their Linkages at Business Cycle Frequencies." Transportation Research Record. The National Academies, No. 1864, (2004): 103-111.

Moore, G.H. Business Cycle Indicators. Volume I. Princeton University Press for NBER, Princeton, New Jersey, 1961.

Stock, J.H. and M.W. Watson. "A Probability Model of the Coincident Economic Indicators." Kajal Lahiri and Geoffrey H. Moore eds. Leading Economic Indicators: New Approaches and Forecasting Records. Cambridge: Cambridge University Press (1991): 63-90.

Tamm, F. "An Agenda for Inventories Input to the Leading Composite Index." Kajal Lahiri and Geoffrey H. Moore eds. Leading Economic Indicators: New Approaches and Forecasting Records. Cambridge: Cambridge University Press (1991): 429-461.

Zarnowitz, V. Business Cycles: Theory, History, Indicators, and Forecasting. The University of Chicago Press, Chicago, 1992.

Zarnowitz, V. and C. Boschan. "Cyclical Indicators: An Evaluation and New Leading Indexes." Business Conditions Digest, (May, 1975): v-xiv.

Zarnowitz, V. and A. Ozyildirim. "Time Series Decomposition and Measurement of Business Cycles, Trends and Growth Cycles.” NBER Working Paper \#8736, 2002. 
Vincent Yao is a senior research economist and director of the transportation and logistics program within the Institute for Economic Advancement at the University of Arkansas, Little Rock. Yao conducts applied research on transportation for the trucking industry, state and federal governments. His research interests include highway finance, forecasting, trade corridor, and economic impacts.

Brian Sloboda is an economist at the U.S. Department of Transportation, Bureau of Transportation Statistics (BTS) in Washington, D.C. Prior to joining BTS, Sloboda was an economist at the U.S. Department of Commerce, Bureau of Economic Analysis. He is currently on the board for the Society of Government Economists (SGE) and the Federal Forecasters Consortium (FFC). Sloboda is an adjunct professor at the University of Phoenix Maryland campus and the University of Maryland University College. 